профессионального самочувствия позволяет сделать вывод о том, что приобретенная воспитателем эмоциональная защита - яркое свидетельство эмоционального выгорания, характеризующего наличие профессиональной деформации личности, которая отрицательно сказывается на субъектах профессионального взаимодействия, психологической атмосфере в педагогических коллективах и результатах педагогической деятельности. Эмоциональное выгорание у воспитателей ДОУ в большей степени, обусловлено факторами профессиональной деятельности, ее спецификой и «вредностями» педагогической профессии. Учитывая сложность и поэтапность формирования профессиональных деформаций в виде эмоционального выгорания, необходима комплексная система мер по профилактике и коррекции деструктивных новообразований личности воспитателя.

\title{
Литература
}

1. Бойко В. В. Диагностика эмоционального выгорания личности /В. В. Бойко, Н. П. Фетискин, В. В. Козлов, Г. М. Мануйлов. Социальнопсихологическая диагностика развития личности и малых групп. М.: Изд-во Ин - та психотерапии. 2002.

2. Дубиницкая К. А. Особенности проявления феномена профессионального выгорания у воспитателей детского сада // Социальная психология малых групп: Материалы I всероссийской научно-практической конференции, посвященной памяти профессора А. В. Петровского. /Отв. ред. М. Ю. Кондратьев.- М: МГППУ, 2009.

3. Звездина Г. П. Эмоциональное выгорание у воспитателей ДОУ // Управление ДОУ. - 2004. - № 4.

4. Костин Е. Ю. Эмоциональное выгорание в профессиональной деятельности педагогов дошкольного образовательного учреждения // Вестник Московского государственного гуманитарного университета им. М. А. Шолохова. Педагогика и психология, 2013. № 2.

5. Котова. Е. В. Профилактика синдрома эмоционального выгорания. учебное пособие / Краснояр.гос. пед. Ун-т им. В. П. Астафьева. - Красноярск, 2013.

\section{ПОВСЕДНЕВНЫЕ СТРЕССОРЫ И ЛОКУС КОНТРОЛЯ В ПЕРИОД ПОЗДНЕЙ ВЗРОСЛОСТИ: СРАВНИТЕЛЬНЫЙ АНАЛИЗ ЖИТЕЛЕЙ САНКТ-ПЕТЕРБУРГА И АРХАНГЕЛЬСКА}

Стрижицкая О.Ю.

Ритм жизни современного человека отличается высокой интенсивностью. Среди череды повседневных дел и задач встречаются те, которые вызывают у нас дискомфорт, напряжение, избыточную усталость, оказывая тем самым влияние на наше самочувствие, физическое и психическое функционирование. Эти закономерности характерны для всех периодов взрослости, однако, в период поздней взрослости (45 - 60 лет), повседневный стресс накладывается на трудности, связанные с постепенным переходом от периода взрослости к старению, и связанными с этим изменениями [3]. 
Результаты исследований, посвященных соотношению повседневного стресса и возраста, носят противоречивый характер. С одной стороны, выявлено, что у молодых людей в жизни больше повседневных стрессоров, чем у пожилых [4]; с другой стороны, с возрастом усиливается уязвимость человека к негативным последствиям повседневного стресса [6]; наконец, в некоторых исследованиях не было получено никаких различий между повседневным стрессом в периоды ранней и поздней взрослости [7].

Исследования, посвященные ресурсам и стратегиям совладания, также не отличаются однозначностью. Достаточно широко исследованы связи повседневного стресса и его позитивного и негативного эффекта на функционирование человека, значительно меньше работ рассматривает вопросы контроля над ситуацией, как предиктора совладания со стрессом [5], и практически отсутствуют работы, рассматривающие специфику локуса контроля в связи с разными видами повседневного стресса.

Целью исследования было проанализировать связи между повседневными стрессорами, их спецификой в разных регионах России (на примере СанктПетербурга и Архангельска) и локусом контроля.

Методы исследования включали:

- Опросник повседневных стрессоров, разработанный для целей данного исследования. Опросник включает в себя перечень из 82 стрессоров, разделенных на восемь шкал: работа/дела; проблемы во взаимодействии; проблемы с окружающей действительностью; отдых/ досуг; финансы/ материальное благополучие; медицинское/ социальное обслуживание; проблемы по хозяйству; личные неприятности.

- Шкала воспринимаемого стресса-10 [1], с помощью которой оценивались такие параметры как перенапряжение, противодействие стрессу и общий показатель воспринимаемого стресса.

- Опросник уровня субъективного контроля (УСК) [2]

В исследовании приняли участие 99 взрослых, работающих людей в возрасте от 45 до 60 лет $\left(\mathrm{M}_{\text {возраст }}=53\right)$, проживающих в Санкт-Петербурге $(\mathrm{N}=$ $\left.48 ; \mathrm{M}_{\text {возраст }}=54\right)$ и Архангельске $\left(\mathrm{N}=51 ; \mathrm{M}_{\text {возраст }}=52\right)$.

Сравнительный анализ степени выраженности отдельных стрессоров и воспринимаемого стресса не выявил различий между выборками СанктПетербурга и Архангельска. Тем не менее, ранговый анализ стрессоров показал, что как для Санкт-Петербурга, так и для Архангельска на первом месте стоят стрессоры, связанные с работой. Это может быть обусловлено как значимостью данной сферы для взрослого человека в целом, так и относительной неопределенностью в данной сфере в период поздней взрослости в преддверии выхода на пенсию или принятия решения о продолжении профессиональной деятельности. Сходные позиции также имеют стрессоры, связанные с межличностными отношениями и окружающей действительностью (3-е и 4-е место соответственно) и стрессоры, связанные с отдыхом и социальным и медицинским обслуживанием (7-е и 8-е место соответственно). Наиболее яркие ранговые различия были получены по стрессорам, связанным с личными 
делами и финансами. Так, для Санкт-Петербурга, личные стрессоры заняли 2-е место, в то время как финансовые лишь 6-е, а в Архангельске наблюдалась обратная картина - финансовые стрессоры заняли 2-е место, а личные - 5-е.

Анализ локуса контроля в группах показал, что и для Санкт-Петербурга и для Архангельска характерен пограничный локус контроля на стыке экстернального и интернального. При этом наиболее низкие показатели (т.е. в большей степени экстернальный локус контроля) в обеих группах были продемонстрированы по показателю «интернальность в межличностных отношениях». Эти результаты отчасти согласуются с результатами, полученными в диссертации Стрижицкой [3], согласно которым в период поздней взрослости наблюдается постепенной снижение показателей локуса контроля.

Корреляционный анализ соотношения показателей повседневных стрессоров, воспринимаемого стресса и параметров локуса контроля выявил структурные различия между выборками Санкт-Петербурга и Архангельска. Интересно отметить, что в петербургской выборке все связи были реципрокные, т.е. более выраженный интернальный локус контроля соответствовал меньшей выраженности показателей как повседневного, так и воспринимаемого стресса, и наоборот. В архангельской выборке, наравне с реципрокными связями, были обнаружены прямые связи: между интернальностью в области достижений и выраженностью стрессоров, связанных с работой / делами и отдыхом / досугом.

Для петербургской выборки были выявлены связи между локусом контроля в сфере достижений и такими повседневными стрессорами, как проблемы с окружающей действительностью, с финансами, отдыхом, медицинским и финансовым обслуживанием, а также личными стрессорами. Также была обнаружена связь между финансовыми стрессорами и локусом контроля в профессиональной сфере. Показатели воспринимаемого стресса были связаны с локусом контроля в сфере достижений и семьи. Однонаправленность полученных связей позволяет предположить, что при относительно небольшой интенсивности повседневных стрессоров и воспринимаемого стресса, человек ощущает больший контроль над ситуацией. С другой стороны, локус контроля, будучи относительно устойчивой личностной характеристикой, может приводить к тому, что при более интернальном локусе контроля в целом, человек склонен воспринимать как стрессовое меньшее число событий, поскольку чувствует больший контроль над ситуацией.

Для архангельской выборки были характерны более разнообразные связи с локусом контроля. Так, были обнаружены реципрокные связи между показателями воспринимаемого стресса и локусом контроля в областях достижений, неудач, семьи и межличностных отношений. Были выявлены реципрокные связи между повседневными стрессом, связанным с медицинским / социальным обслуживанием и локусом контроля с области здоровья, а также стрессорами, связанными с хозяйством и локусом контроля в межличностных отношениях. Как и в случае с петербургской выборкой, мы можем допустить, 
что более интернальный локус контроля, свидетельствующий о чувстве большего контроля над ситуацией, позволяет воспринимать меньшее число событий как стрессовые. Прямая связь между локусом контроля в сфере достижений и стрессорами, связанными с работой и отдыхом, может говорить о том, что в данном случае попытки контролировать ситуацию могут выступать негативным фактором и приводить к возникновению большего числа стрессовых ситуаций.

Полученные результаты позволяют говорить о том, что, с одной стороны, выраженность повседневного стресса в различных регионах, например, в Санкт-Петербурге и Архангельске для людей периода поздней взрослости примерно одинакова. Однако, структура стрессоров, а также их взаимосвязи с различными факторами могут различаться.

Наши результаты позволяют говорить о том, что локус контроля играет определенную роль в переживании повседневного стресса и может, в некоторых случаях, выступать предиктором интенсивности переживания повседневных стрессоров. Однако, полученные результаты не дают возможности дать исчерпывающее описание характеру взаимосвязи между локусом контроля и повседневными стрессорами.

Следует отметить некоторые ограничения данного исследования. К ним можно отнести небольшой объем выборки выделенных групп, в связи с чем не представлялось возможным провести более дифференцированный анализ роли различных социально-демографических факторов, которые могли оказывать дополнительное влияние на соотношение показателей локуса контроля и повседневных стрессоров.

Исследование выполнено при поддержке фонда РНФ, грант 16-18-10088 «Комплексное изучение стрессоров повседневной жизни и ресурсы их преодоления в разные периоды взрослости»

\section{Литература}

1. Абабков В.А., Барышникова К., Воронцова-Венгер О.В., Горбунов И.А., Капранова С.В., Пологаева Е.А., Стуклов К.А. Валидизация русскоязычной версии опросника «Шкала воспринимаемого стресса-10» // Вестник Санкт-Петербургского университета. Серия 16. Психология. Педагогика. 2016. № 2. С. 6-15.

2. Практикум по возрастной психологии / под ред. Л.А. Головей, Е.Ф. Рыбалко. - 2001. - СПб: Речь. - С.518 - 522.

3. Стрижицкая О.Ю. Самоотношение и временная трансспектива личности в период поздней взрослости. Диссертация на соискание ученой степени кандидата психологических наук. - СПб: СПбГУ. - 2006. - 221 с.

4. Almeida D.M., Horn M.C. Is daily life more stressful during middle adulthood?// In O.G. Brim, C.D. Ryff, R.C. Kessler (Eds.), How healthy are we? A national study of well-being at midlife. - 2004. - Chicago: University of Chicago Press. - (pp. 425-451).

5. Diehl M., Hay E.L. Risk and Resilience Factors in Coping With Daily Stress in Adulthood: The Role of Age, Self-Concept Incoherence, and Personal 
Control // Developmental Psychology. - 2010. - Vol. 46, №5. - P. 1132-1146. doi:10.1037/a0019937

6. Mroczek D.K., Almeida D.M. The effect of daily stress, personality, and age on daily negative affect // Journal of Personality. - 2004. - Vol. 72. - P. 355378.

7. Stawski R.S., Sliwinski M.J., Almeida D.M., Smyth J.M. Reported exposure and emotional reactivity to daily stressors: The roles of adult age and global perceived stress // Psychology and Aging. - 2008. - Vol. 23. - P. 52-61.

\section{ЭМОЦИОНАЛЬНЫЕ ОСОБЕННОСТИ АДДИКТИВНОГО ПОВЕДЕНИЯ ПОДРОСТКОВ С ЗАВИСИМОСТЬЮ. (МНОГОПОЛЬЗОВАТЕЛЬСКИЕ ИГРЫ)}

Туисов С.И. Научный руководитель: к.п.н., доцент Новикова С.С.

Уровень развития компьютерных технологий и программного обеспечения способен создать виртуальную реальность для мозга, в которую погружается человек, находясь за компьютером. Компьютерная реальность может полностью овладеть вниманием индивида и изолировать его от окружающего мира. Компьютерная зависимость не может быть однозначно отнесена к зависимостям, так как компьютер является лишь средством, которое позволяет осуществлять различные виды деятельности, и без ее конкретизации говорить о зависимости было бы неверным. [4]

Борьба между игровыми компаниями за рынок игроков со всего мира привела к тому, что игры стали представлять собой сложные системы управления человеческими ресурсами. К примеру многопользовательская ролевая онлайн-игра (MMORPG - massively multiplayer online role-playing game), механика которой состоит во «вхождении» человека в игру, интеграции с компьютером, потере индивидуальности и отождествлении себя с компьютерным персонажем. На последней стадии игровой зависимости человек теряет чувство времени, происходят сдвиги в пирамиде потребностей. Таким образом в октябре 2005 года умерла от истощения китайская девочка после многосуточной игры. В самой игре прошли виртуальные похороны. [1] И это не единственный пример компьютерной зависимости у подростков, следствием которой стал смертельный исход.

После адаптации к правилам и нормам, существующим в игре, человек начинает переносить свои усилия с решения игровой задачи на межличностное взаимодействие с партнерами. С точки зрения социальной психологии, такое взаимодействие является вполне адекватным, так как общение строится на основе определенной совместной деятельности, которая должна иметь осознаваемую цель, а также мотивы. Если мы посмотрим на современную социальную ситуацию, то увидим, что обучение в школе (как, впрочем, и в вузе) имеет крайне смутные для ребенка цели, кроме, собственно, получения аттестата/диплома. Жизненная неопределенность, отсутствие видимых перспектив, нестабильная экономическая обстановка приводят к тому, что 